\title{
Are AIMS65 and glasgow-blatchford scores useful in predicting health costs in patients admitted to emergency department with acute upper gastrointestinal bleeding: A prospective and observational study
}

\author{
Hayrullah YÖNAK* ${ }^{\circledR}$, Serdar ÖZDEMİ ${ }^{\circledR}$, Kamil KOKULU ${ }^{\oplus}$, Hatice Şeyma AKÇA®, Mehmet Muzaffer İSLAM ${ }^{\circledR}$, \\ Abdullah ALGIN ${ }^{(i D}$, Murad YUNUSOV ${ }^{\circ}$, Serkan Emre EROĞLU \\ Department of Emergency Medicine, Ümraniye Education and Research Hospital, University of Health Sciences, Istanbul, Turkey
}

\begin{abstract}
Received: $04.02 .2021 \quad \bullet \quad$ Accepted/Published Online: 18.02.2021 • Final Version: 23.04 .2021
Abstract

We aimed to investigate the use and superiority of AIMS65 (Albumin, INR, Alteration in mental status, Systolic blood pressure, age) and GlasgowBlatchford scores (GBS) in predicting hospital health costs in patients admitted to emergency department with upper gastrointestinal bleeding. Patients above the age of 18 who were admitted to the Emergency Department of Ümraniye Training and Research Hospital between 01.06 .2018 and 31.05.2019, who were diagnosed with upper gastrointestinal bleeding were included in the study. Patients' calculations of AIMS65 and GBS were recorded. Pearson's Chi-square test was used, and statistical significance was assessed. A total of 151 patients included in the study, 109 (72.2\%) were male. Of the patients 2(1.3\%) were discharged from the emergency department and 7 (4.6\%) were exitus. According to AIMS65 risk scoring, costs of emergency department and inpatient clinics and total clinical costs were higher in high risk group compared to the low risk group $(p=0.007, p=0.007$ and $p=0.003$ respectively). The costs of emergency department and inpatient clinic and total costs were found statistically significantly different between GBS groups ( $<<0.001, \mathrm{p}=0.019$, and $\mathrm{p}=0.001$ respectively). AIMS65 risk score and GBS have been revealed to be useful in predicting the costs of emergency department and inpatient clinics and total clinical costs for patients with upper gastrointestinal bleeding
\end{abstract}

Keywords: emergency department, aims65, glasgow-blatchford bleeding score, health cost

\section{Introduction}

Expenses in healthcare services increase as the need for healthcare services increases, which requires efficient use and improvement of available resources (Zengin et al., 2013). In 2014, the Turkish Ministry of Development prepared a report called "Improvement of Healthcare Services and Fiscal Sustainability" within the scope of ten-year development plan. In this report, the increase in health costs was emphasized and recommendations to provide fiscal sustainability were included (T.C. Kalkınma Bakanlığı Onuncu Kalkınma Planı). The rate of examinations performed in the emergency department is $25.97 \%$ in our country (İstatistik, Analiz, Raporlama ve Stratejik Yönetim Dairesi Başkanlığı.) There are only a limited number of studies on cost analyses of emergency departments. It is really hard to calculate quality and cost of the service precisely. Emergency medical interventions, laboratory use, medical equipment and services range from person to person for patients admitted to the emergency departments (Williams, 1996). Upper gastrointestinal bleeding (UGIB) has an important place in admissions to the emergency department. As well as gastrointestinal diseases, the drugs used, and comorbid diseases also affect the duration and severity of upper gastrointestinal bleedings. Meteorological changes also caused more frequent admissions in specific months of the year. Different clinics may have different approaches in predicting clinical costs of upper gastrointestinal bleedings which have an important place in morbidity and mortality, and which may cause hospital stay to extend.

Our study aimed to investigate whether AIMS65 and Glasgow-Blatchford scores (GBS) that were used to predict mortality in patients admitted to the emergency department with upper gastrointestinal bleeding were useful in predicting emergency department, inpatient clinic and total clinical costs and reveal the relationship of these costs with emergency treatments and demographic data.

\section{Materials and methods}

\subsection{Patient population}

Patients above the age of 18 who were admitted to the Emergency Department of Ümraniye Training and Research Hospital between 01.06.2018 and 31.05.2019, who were diagnosed with upper gastrointestinal bleeding, who accepted 
to participate in the study (the consents of unconscious patients were provided by their relatives), who were not followed up with a comorbid disease during admission and who were admitted to hospital within the first 24 hours after onset of the symptoms were included in the study. Patients with missing data and patients with a comorbid disease that may affect the treatment were excluded from the study.

\subsection{Data collection}

Expenses incurred by the health institution for patients were obtained from hospital information system and recorded in the patient forms as costs of emergency department and inpatient clinic in which the patient was hospitalized (ward or intensive care unit) and total clinical costs (total of these two costs). Patients' age, gender, month of admission, complaints and vital parameters during admission, drugs used, emergency department outcome, status and time of blood transfusion in the emergency department or clinics, status and time of endoscopy, laboratory parameters, GBS, AIMS65 score, and emergency department, inpatient clinic and total clinical costs were recorded. Arterial pressure, oxygen saturation and pulse were recorded as vital parameters. Emergency department outcomes were grouped as discharge from the emergency department, hospitalization in ward, hospitalization in intensive care unit, follow-up and mortality during treatment process. The drugs that have a role in the etiology of upper gastrointestinal bleeding were grouped as acetylsalicylic acid (ASA), non-steroidal anti-inflammatory drugs (NSAID), anticoagulant drugs, combination of these drugs and none of these drugs. Complaints of patients during admission to the emergency department were grouped as melena, syncope, black vomit, vomiting blood, dizziness, hematochezia, occult blood in the stool, incidental and coexistence of these. Hemoglobin, INR, and albumin values during admission were recorded as laboratory parameters of the patients.

\subsection{Statistical analysis}

IBM SPSS Statistics for Mac, version 26 (IBM Corp., Armonk, N.Y., USA) software program was used for statistical analyses of the data obtained in the study. Whether continuous data were normally distributed was determined with KolmogorovSmirnov test. Normally distributed continuous data were expressed with mean and standard deviation and non-normally distributed continuous data with median and interquartile range (IQR). Whether there was a difference between two groups was analyzed with Mann Whitney $U$ test for continuous variables. Kruskal-Wallis test was used in the assessment of the relationship between subgroups for non-normally distributed continuous variables. When a statistical significance was found between subgroups in Kruskal-Wallis test Bonferroni correction was used and the significance level was accepted as $\mathrm{p}<0.05$.

\section{Results}

After exclusion criteria were applied a total of 151 patients were included in the study (Fig. 1). Ages of the patients included in the study ranged from 20 to 99 and their median age was 64 (IQR: 45-75). While median age of male patients was 61 (IQR: $42.5-71)$ years median age of female patients was 69.5 (IQR: 52.7-80.2) years. Of the patients, 109 (72.2\%) were male and $42(27.8 \%)$ were female. The most common complaint during admission of the patients was melena (Fig. 2).

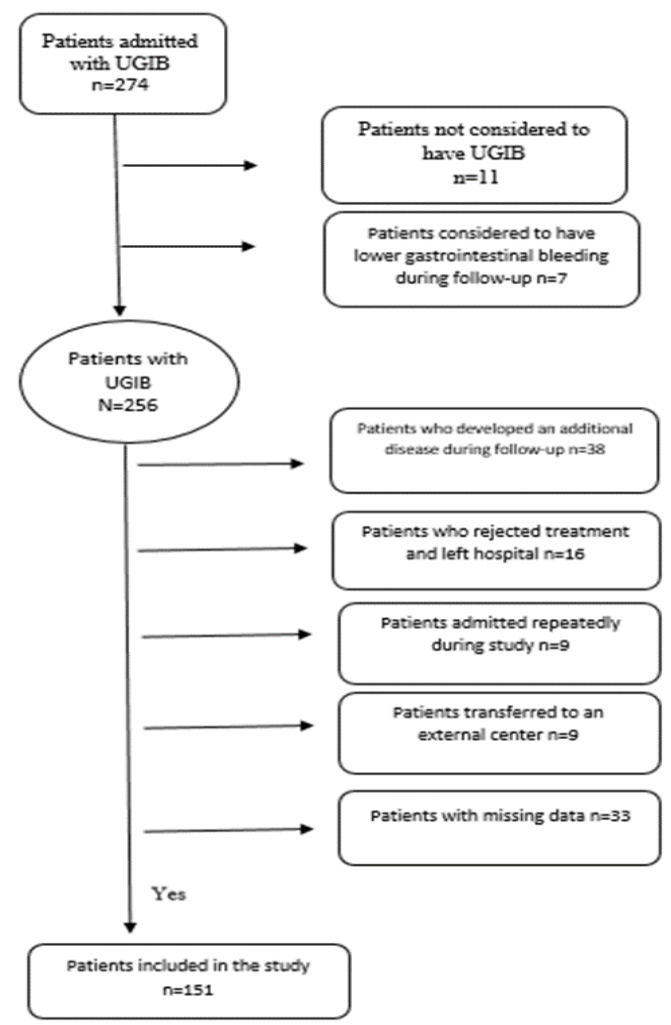

Fig.1. Flow chart

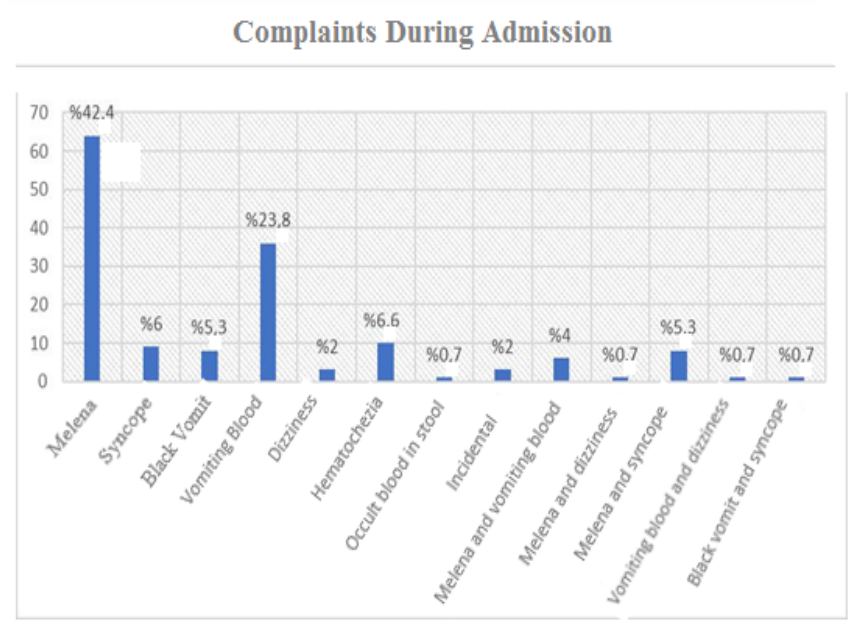

Fig.2. Complaints of patients during the first admission

Distribution of viral and laboratory parameters and AIMS65 scores and GBS of the patients during admission were summarized in Table 1. Of the admissions to emergency department, 92.7\% $(n=141)$ resulted in discharge after followup on the ward. Mortality rate was $4.6 \%(n=7)$ (Fig. 3). In current study, patients' costs in emergency department, costs in inpatient clinics and total costs when they were in the hospital were analyzed as three categories in terms of GBS and AIMS65 score and a statistically significant positivity and 
weak correlation were found for both scoring systems (Table 2).

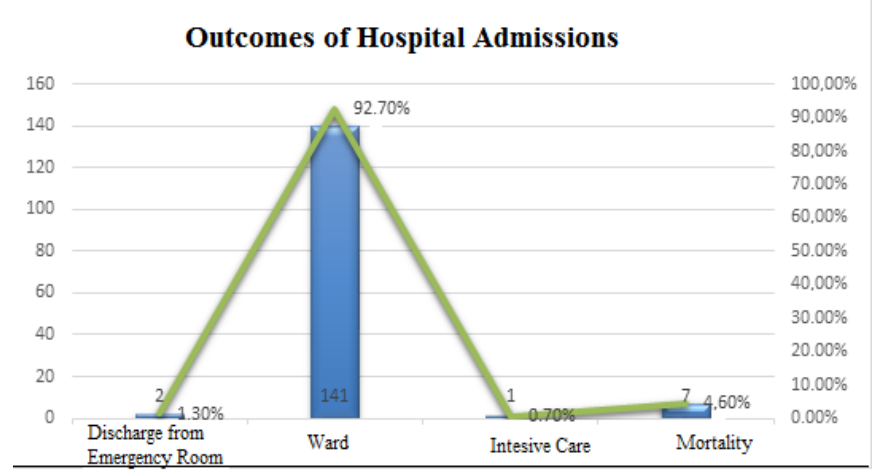

Fig. 3. Outcomes of hospital admissions

Table 1. Viral parameters, test results and scores of patients during admission

\begin{tabular}{|c|c|}
\hline Parameters & Values \\
\hline Age & $64(45-75)$ \\
Male & $109(72.2 \%)$ \\
\hline Level of Consciousness (GCS) & $15(15-15)$ \\
SBP (mmHg) & $119.38 \mathrm{mmHg}$ \\
& $( \pm 26.1 \mathrm{mmHg})$ \\
DBP $(\mathrm{mmHg})$ & $67.99 \mathrm{mmHg}$ \\
Pulse $(\mathrm{bpm})$ & $( \pm 15.06 \mathrm{mmHg})$ \\
Saturation $0_{2}(\%)$ & $91 \mathrm{bpm}(80-103 \mathrm{bpm})$ \\
Hemoglobin $(\mathrm{g} / \mathrm{dl})$ & $98 \%(96-99)$ \\
BUN $(\mathrm{mg} / \mathrm{dl})$ & $9.41( \pm 2.82)$ \\
INR & $66.3(42.8-92.0)$ \\
Albumin (mg/dl) & $1.1(1.0-1.2)$ \\
AIMS65 Score & $3.27( \pm 0.59)$ \\
Glasgow-Blatchford Score & $1(0-2)$ \\
\hline
\end{tabular}

Table 2. Correlation analysis of disease scores and patient costs

\begin{tabular}{|c|c|c|c|c|c}
\hline $\begin{array}{c}\text { Cost } \\
\text { AIMS65 } \\
\text { Score }\end{array}$ & $\mathrm{p}$ & $\mathrm{r}$ & $\begin{array}{c}\text { Cost } \\
\text { GBS }\end{array}$ & $\mathrm{p}$ & $\mathrm{r}$ \\
\hline $\begin{array}{c}\text { Emergency } \\
\text { Department }\end{array}$ & 0.001 & 0.26 & $\begin{array}{c}\text { Emergency } \\
\text { Department }\end{array}$ & $<0.001$ & 0.39 \\
Clinic & $<0.001$ & 0.30 & Clinic & 0.001 & 0.27 \\
Total & $<0.001$ & 0.32 & Total & $<0.001$ & 0.35
\end{tabular}

Table 3. Distribution of costs according to AIMS65 risk groups

\begin{tabular}{|l|c|c|c|c|c|}
\hline \multicolumn{1}{|c|}{ Cost } & $\begin{array}{c}\text { Aims65 } \\
\text { Low } \\
\text { Risk } \\
\text { Median }\end{array}$ & $\begin{array}{c}\text { Aims65 } \\
\text { Low } \\
\text { Risk } \\
\text { Iqr }\end{array}$ & $\begin{array}{c}\text { Aims65 } \\
\text { High } \\
\text { Risk } \\
\text { Median }\end{array}$ & $\begin{array}{c}\text { Aims65 } \\
\text { High } \\
\text { Risk } \\
\text { Iqr }\end{array}$ & P \\
\hline $\begin{array}{l}\text { Costs of } \\
\text { Emergency } \\
\text { Department }\end{array}$ & 748.22 & $375.67-$ & 1171.38 & $667.91-$ & 0.007 \\
\hline $\begin{array}{l}\text { Costs of } \\
\text { Non- }\end{array}$ & 1133.32 & & & 1514.37 & \\
$\begin{array}{l}\text { Emergency } \\
\text { Clinics }\end{array}$ & 1499.23 & $620.90-$ & 2278.56 & $1379.01-$ & 0.007 \\
\hline $\begin{array}{l}\text { Total } \\
\text { Clinical } \\
\text { Costs }\end{array}$ & 23766.05 & $1322.32-$ & 3427.76 & $2515.91-$ & 0.003 \\
\hline
\end{tabular}

According to AIMS65 scores, 68.2\% $(n=103)$ of the patients were grouped as low risk (score $0-1)$ and $31.8 \%(n=48)$ as high risk (score 2-5). AIMS65 score was statistically significantly different between low and high-risk groups in terms of emergency department, inpatient clinic, and total clinical costs $(\mathrm{p}=0.007, \mathrm{p}=0.007$ and $\mathrm{p}=0.003$ respectively) (Table 3). According to GBS, 35.1\% $(\mathrm{n}=53)$ of the patients were grouped as low score (score $0-10), 34.4 \%(n=52)$ as moderate score (score 11-13) and 30.5\% $(\mathrm{n}=46)$ as high score (score 14-23) and a statistically significant difference was found between GBS groups in terms of emergency department, inpatient clinic, and total costs $(<0.001, \mathrm{p}=0.019$, and $\mathrm{p}=0.001$ respectively) (Table 4).

When mean costs per patient were assessed according to emergency department, inpatient clinic, and total costs in terms of AIMS65 score an increase was observed in the costs with increasing scores. When statistical significance and clinical correlation were assessed in terms of genders for AIMS65 score and GBS separately a statistically significant positivity and weak correlation were found between AIMS65 score and emergency department, inpatient clinic, and total clinical costs in male gender $(\mathrm{p}=0.002, \mathrm{r}=0.30 ; \mathrm{p}=0.005, \mathrm{r}=0.27 ; \mathrm{p}=0.001$, $\mathrm{r}=0.32$ respectively) (Spearman's correlation test). While a statistically significantly positive difference and weak correlation were found between GBS of male gender and inpatient clinic and total clinical costs a moderate degree of correlation was observed in terms of emergency department costs $(\mathrm{p}<0.001, \mathrm{r}=0.46 ; \mathrm{p}=0.008, \mathrm{r}=0.25 ; \mathrm{p}<0.001, \mathrm{r}=0.35$ respectively) (Spearman's correlation test). A statistically significant positivity was found in AIMS65 score and GBS of female gender in terms of inpatient clinic and total clinical costs. While AIMS65 score was correlated with inpatient clinic cost at a moderate degree a weak correlation was found in GBS ( $\mathrm{p}=0.005, \mathrm{r}=0.43 ; \mathrm{p}=0.44, \mathrm{r}=0.32$ respectively) (Spearman's correlation test). Total clinical costs were weakly correlated in AIMS65 and GBS systems ( $r=0.39$ and $r=0.35$ respectively) (Spearman's correlation test). When the correlation of emergency department costs was assessed in female gender no statistically significant result was found in AIMS65 and GBS systems ( $\mathrm{p}>0.263$ and $\mathrm{p}<0.138$ respectively).

\section{Discussion}

We concluded in our study that AIMS65 score could be used in predicting the costs. When we compared the patients in terms of their AIMS65 risk score (score 0-5) they had during admission to the emergency departments, emergency department cost, inpatient clinic cost and total clinical costs a gradually increasing average cost table was obtained in terms of expenses incurred by the health institution within the process from admission to discharge. When patients were divided into low risk (0-1) and high risk (2-5) groups according to their AIMS65 risk score they had during admission the expenses incurred by the health institution significantly increased in terms of emergency department, inpatient clinic and total clinical costs. 
Table 4. Distribution of costs according to GBS risk groups

\begin{tabular}{|c|c|c|c|c|c|c|c|}
\hline $\begin{array}{l}\text { Risk } \\
\text { Scoring }\end{array}$ & $\begin{array}{c}\text { Gbs } \\
\text { Low Risk } \\
\text { Median }\end{array}$ & $\begin{array}{c}\text { Gbs } \\
\text { Low Risk } \\
\text { Iqr }\end{array}$ & $\begin{array}{c}\text { Gbs } \\
\text { Moderate Risk } \\
\text { Median }\end{array}$ & $\begin{array}{c}\text { Gbs } \\
\text { Moderate Risk } \\
\text { Igr }\end{array}$ & $\begin{array}{c}\text { Gbs } \\
\text { High Risk } \\
\text { Median }\end{array}$ & $\begin{array}{c}\text { Gbs } \\
\text { High Risk } \\
\text { Iqr }\end{array}$ & $P$ \\
\hline $\begin{array}{l}\text { Emergency } \\
\text { Department Costs }\end{array}$ & $475.92^{\mathrm{a}, \mathrm{b}}$ & $\begin{array}{l}375.12- \\
816.39\end{array}$ & $994.59^{c}$ & $\begin{array}{l}460.66- \\
1526.08\end{array}$ & 1164.05 & $\begin{array}{l}757.22- \\
1446.18\end{array}$ & $<0.001$ \\
\hline $\begin{array}{l}\text { Non-Emergency } \\
\text { Clinic Costs }\end{array}$ & $1396.39^{\mathrm{d}, \mathrm{e}}$ & $12-2294.99$ & $2579.94^{f}$ & $\begin{array}{l}1082.00- \\
3667.56\end{array}$ & 1795.33 & $\begin{array}{l}1236.18- \\
2658.01\end{array}$ & 0.019 \\
\hline $\begin{array}{l}\text { Total Clinical } \\
\text { Costs }\end{array}$ & $1794.00^{\mathrm{x}, \mathrm{y}}$ & $\begin{array}{l}590.03- \\
3135.45\end{array}$ & $3605.02^{z}$ & $\begin{array}{l}1958.51- \\
4831.60\end{array}$ & 2895.83 & $\begin{array}{l}2340.31- \\
3776.15\end{array}$ & 0.001 \\
\hline
\end{tabular}

a-Low and moderate risk group $\mathrm{p}$ value $=0.002$, b-Low and high risk group $\mathrm{p}$ value $<0.001, \mathrm{c}$ - Moderate and high risk group $\mathrm{p}$ value $>0.05, \mathrm{~d}-$ Low and moderate risk group $\mathrm{p}$ value $=0.22$, e- Low and high risk group $\mathrm{p}$ value $=0.017, \mathrm{f}-$ Moderate and high risk group $\mathrm{p}$ value $>0.05, \mathrm{x}-\mathrm{Low}$ and moderate risk group $p$ value $=0.021, y$ - Low and high risk group $p$ value $=0.002, z$ - Moderate and high risk group $p$ value $>0.05$

When we compared patients in terms of their GBS which was another UGIB risk score calculated in our study we observed a statistical increase in emergency department, inpatient clinic and total clinical costs. When this score was divided into three groups as low, moderate and high cost a difference was found between the emergency department and total clinical costs in the low risk group among the subgroups although a statistical significance was found in the three groups in predicting the emergency department, inpatient clinic and total clinical costs. We think this is because of the number of patients and the underlying disease that causes bleeding. As the need for health care services increases the expenses in healthcare service increase as well. Regardless of whether they are seeking profit or not, service costs must be properly defined (Zengin et al., 2013). All expenses (including substructure, personnel, management and food expenditures) must be determined to obtain a real profit and loss statement (Özdemir et al., 2020). Emergency medical interventions, laboratory use, medical equipment and services range from person to person for patients admitted to the emergency departments. Therefore, it is hard to follow up an efficient cost analysis for carrying out emergency services. Williams et al. revealed in their study in which the difference between medical emergency patients and inpatient patients was investigated that the profit per patient was higher for patients who were admitted as a real emergency (Williams et al., 1996). Cremonesi et al. (2015) reported in their studies in which they investigated the cost difference between triage codes that the cost of real emergency patients was higher, but unit income and profit gained from patients were not. In our study, emergency department costs were observed to increase by the increasing risk score. Due to inadequate number of total admissions and absence of patients in each score, we could not calculate emergency department, inpatient clinic, and total clinical costs separately according to patients' GBS calculated during their admission to the emergency department. Therefore, we could not assess how much the costs increased according to GBS of patients.

There are a large number of scoring methods used to determine several risks, such as mortality and duration of hospital stay in a life-threatening disease like UGIB. We believe that AIMS65 which we used in our study will be helpful in predicting the costs in a healthcare institution as it does not contain many scorings. While GBS is useful in calculating an average cost for healthcare costs of patients as it contains many scorings and parameters, we think it is not useful if different calculations will be made for each score. It is better to perform a study with larger number of patients due to limitations in our study. However, to the best of our knowledge, our study is the first study in which efficiency of the scorings used as mortality risk scores in patients with UGIB in predicting the costs that will be incurred by the health institution and utility of these scores in cost analysis have been assessed.

Previous studies revealed that UGIB was more common in male gender (Davarci et al., 2019; Kuşçu et al., 2019). In our study, $72.2 \%(\mathrm{n}=109)$ of the patients were male and ages of the patients ranged from 20 to 99 , which is consistent with studies in literature. Median age of the patients was 64 (IQR: 45-75). Although a statistically significant correlation was found between male and female patients in terms of emergency department, inpatient clinic and total clinical costs in our study this statistically significant relationship may not be clinically significant as correlation coefficients were low. We believe the relationship between genders and emergency department; inpatient clinic and total clinical costs must be revealed with larger study groups.

In a study in which admissions to emergency department with UGIB were retrospectively evaluated, $44.8 \%$ of the patients were admitted to the emergency department with melena and the least common reason for admission was syncope (1\%). Melena was found in $67.6 \%$ of the patients on their rectal examination independent from the complaint during admission (Uysal et al., 2019). In our study, the most common reason for admission to the emergency department was melena (42.4\%), which is similar to admission complaints in literature. The number of patients who had melena on rectal examination was $99(65.6 \%)$. In the retrospective study by Uysal et al. (2019) comorbidities of UGIB were reported as hypertension $(32.9 \%)$, diabetes mellitus $(17.4 \%)$, coronary artery disease $(22.6 \%)$, congestive heart failure $(6.9 \%)$ and liver cirrhosis $(25.2 \%)$. In a review by Van Leerdam (2008), the rate of severe or life-threatening comorbidities was higher than $40 \%$ in $40 \%$ of the patients with UGIB. In our study, comorbidities of patients admitted with UGIB to the emergency department were hypertension (35.8\%), diabetes 
mellitus $(17.9 \%)$, coronary artery disease $(22.5 \%)$, congestive heart failure (7.9\%), liver failure during admission (7.9\%) and diagnosis of liver failure $(9.9 \%)$.

Several studies have revealed that meteorological factors increase the risk of bleeding in diseases associated with bleeding in cold weather (Lenzen et al., 2017; Prechter et al., 2019). According to the months of admission to the emergency department, the number of admissions was the lowest in summer months $(15.2 \%)$ in our study, which is similar to findings of other studies. Mortality and morbidity increase in UGIB with ranging prognosis due to late admission of the patient to emergency department, late diagnosis and lack of opportunities for examination (Yalçın et al., 2016). In our study, $92.7 \%$ of admissions to the emergency department resulted in discharge after follow-up on the ward. Mortality

\section{References}

1. Cremonesi, P., Di Bella, E., Montefiori, M., Persico, L., 2015. The robustness and effectiveness of the triage system at times of overcrowding and the extra costs due to inappropriate use of emergency departments. Appl. Health Econ. Health Policy. 13, 507-514.

2. Davarci, P. Z., Davarci, I., Sazli, H., 2019. Comparison of AIMS65 and rockall scoring systems for predicting mortality in patients with upper gastrointestinal system hemorrhage. Annals Med. Res. 26(9), 2068-2071.

3. İstatistik, Analiz, Raporlama ve Stratejik Yönetim Dairesi Başkanlığı. 'Her Branşta İlk 100 Hastane' 2017 Yılı Ocak-Ekim Dönemi Poliklinik, Yatış, Yoğun Bakım ve Acil Servis İstatistikleri, Ankara.

4. Kuşcu, Ö.Ö., Elmas, D., Erdoğan, M., Benli, B.A., 2019. Karaoğullarından, Ü., İnal, M.A. et al. Retrospective evaluation of critical care patients with upper gastrointestinal system bleeding. J. Medical and Surg. Intensive Care Med. 10(3), 80.

5. Lenzen, H., Musmann, E., Kottas, M., Schönemeier, B., Köhnlein, T., Manns, MP, Lankisch TO., 2017. Acute gastrointestinal bleeding cases presenting to the emergency department are associated with age, sex and seasonal and circadian factors. Eur. J. Gastroenterol. Hepatol. 29(1), 78-83.

6. Özdemir, S., Altunok, İ., Algın, A., Akça, H., Eroğlu, S., 2020. Acil Servise Başvuran Derin Anemi Olgularının Maliyet Analizi. Abant Tip Dergisi. 9 (2), 24-30. rate was $4.6 \%$. Some patients with UGIB could not be included in our study due to missing forms and data caused by high density in the emergency department. We did not have any information about the reasons of the costs (e.g. personnel, medical equipment, and consumables). As endoscopic results of the patients were not assessed the relationship between etiology and cost could not be found. Expenses in health services increase by the number of individuals admitted to the health institutions. AIMS65 and GBS are useful in predicting health costs in patients admitted to emergency department with acute upper gastrointestinal bleeding.

\section{Conflict of interest}

None to declare.

\section{Acknowledgments}

None to declare.

7. Prechter, F., Bürger, M., Lehmann, T., Stallmach, A., Schmidt, C., 2019. A study on the correlation of gastrointestinal bleeding and meteorological factors is there a weather condition for GI bleeding? Z. Gastroenterol. 57(12), 1476-1480.

8. Uysal, Y., Babus, S.B., Kose, A., Ates, F., Biricik, S., Erdogan, S., Çevik, İ., Toker, İ., Ayrı, C., 2019. The prognostic significance of the risk scores at upper gastrointestinal bleeding. Niger. J. Clin. Pract. 22(8), 1099-1108.

9. T.C. Kalkınma Bakanlığı Onuncu Kalkınma Planı. Sağlık HizmetlerininEtkinliginin Artırılması ve Mali Sürdürülebilirlik Özel İhtisas Komisyon Raporu.

10. Van Leerdam, M.E., 2008. Epidemiology of acute upper gastrointestinal bleeding. Best Pract. Res. Clin. Gastroenterol. 22(2), 209-224.

11. Williams, R.M. The costs of visits to emergency departments. 1996. N. Engl. J. Med. 334 (10), 642-646.

12. Yalçın, M., Kara, B., Öztürk, N.A., Ölmez, Ş., Taşdoğan, B.E., Taş, A., 2016. Epidemiology and endoscopic findings of the patients suffering from upper gastrointestinal system bleeding. Dicle Tip Dergisi. 43(1), 73-76.

13. Zengin, S., Güzel, R., Al, B., Kartal, Ş., Sarcan, E., Yıldırım, C., 2013. Cost analysis of a university hospital's adult emergency service. JAEM. 12, 71-75. 